BULLETIN Bulletin hispanique

HISPANIQUE Université Michel de Montaigne Bordeaux

$112-2 \mid 2010$

Varia

\title{
Blas de Otero Muñoz, Hojas de Madrid con La galerna
}

Galaxia Gutenberg, Círculo de lectores, Barcelona, 2010

\section{Evelyne Martín-Hernández}

\section{CpenEdition}

Journals

Édition électronique

URL : http://journals.openedition.org/bulletinhispanique/1298

DOI : 10.4000/bulletinhispanique. 1298

ISSN : 1775-3821

Éditeur

Presses universitaires de Bordeaux

Édition imprimée

Date de publication : 31 décembre 2010

Pagination : 860-862

ISBN : 978-2-86781-709-0

ISSN : 0007-4640

Référence électronique

Evelyne Martín-Hernández, "Blas de Otero Muñoz, Hojas de Madrid con La galerna », Bulletin hispanique [En ligne], 112-2 | 2010, mis en ligne le 19 janvier 2013, consulté le 22 septembre 2020. URL : http:// journals.openedition.org/bulletinhispanique/1298; DOI : https://doi.org/10.4000/bulletinhispanique. 1298 
Blas de Otero Muñoz, Hojas de Madrid con La galerna. Sabina de la Cruz (edición), Mario Hernández (Prólogo). - Barcelona, Galaxia Gutenberg, Círculo de lectores, 2010, 383 p. - ISBN 978-84-672-3939 (Círculo de Lectores). - ISBN 978-84-8109-857-0 (Galaxia Gutenberg).

Le recueil posthume du poète Blas de Otero, Hojas de Madrid con la Galerna, est sorti au printemps de 2010, dans une belle édition du Círculo de Lectores de Galaxia Gutenberg. Sabina de la Cruz et Mario Hernández, qui en sont les maîtres d'œuvre, ont choisi de présenter les poèmes par ordre chronologique, ce qui donne au livre le caractère d'un journal en vers, tenu depuis le retour du poète à Madrid, en 1968 (après un séjour de quatre ans à Cuba), jusqu'en 1977, deux ans avant sa mort.

Certains textes avaient paru dans diverses revues ou anthologies, mais cette publication, avec la somme des textes qu'elle présente (306) constitue un véritable événement dans le monde littéraire hispanique. Elle donne la note finale de ce qui a été l'une des plus fortes - sinon la plus forte - des voix poétiques de l'Espagne de l'après-guerre civile, en même temps qu'elle révèle la cohérence de l'œuvre.

Dans Hojas de Madrid, le personnage poétique qui se dessine est plus humain que dans les autres recueils, plus proche du lecteur, à cause, peutêtre, des facettes contradictoires qui le façonnent et qu'il livre dans une sorte de conversation familière.

C'est ainsi que l'on retrouve le poète dans la cité, celui de Pido la paz y la palabra et de Que trata de España, toujours indigné par l'injustice, le pouvoir de l'argent, toujours en guerre contre la guerre et en butte à une certaine Espagne " maniatada ", " inarreglable tierra ". Et, dans le même temps, percent le doute, l'inquiétude de celui qui parle depuis "el escéptico sitio del hombre ", qui vacille devant l'incompréhensible "bolero de la historia".

La fidélité à l'idéal révolutionnaire est certes affirmée, en particulier dans la première partie du livre, lorsqu'il parle de Cuba et de la nostalgie qu' elle lui inspire : "El que asi escribe, lestá en España penandoly pensando en el Caribe". Mais le désir du retour en Espagne, à Madrid, au Pays Basque, à la maison maternelle est également lancinant.

Le personnage de la mère est en effet très présent dans ce livre, explicitement ou implicitement, par la métonymie : les lieux qu'elle habite (ciel, vallon du Pays Basque), les espaces-refuges que sont la bibliothèque, l'armoire (qui préfigure El armario de sombras de Gamoneda). C'est la mère âgée, silhouette fragile dont la disparition prévisible redouble la mort annoncée du poète malade, mais c'est aussi la jeune fille qu'elle fut et la jeune femme attirante qui l'a porté. Abri initial et ultime, en elle s'accomplit la trajectoire vitale du 
sujet lyrique : "andar desde el vientre materno hasta debajo de la tierra". Il lui parle parfois, avec sa voix d'enfant : "Mamá, ven, estoy muy solo ".

Car la figure de l'enfant hante aussi ce livre, reliant les dernières années de sa vie aux premières : "y hay un niño que no cesa de mirarme ". Le dialogue s'engage entre le moi et ce fantôme qui fait retour, cet ambivalent " niño perdido".

Hojas de Madrid oscille entre deux pôles : le repli vers le giron maternel, les souvenirs d'enfance, dans une première partie du livre, vers la quiétude du foyer partagé avec la dernière compagne dans une dernière partie, et, d'autre part, l'évocation des voyages, des pays traversés, arpentés, "vagamundeando ". Est-ce le simple regret du passé ou celui de la vie libre et errante qui inspire le récit ressassé des villes et des contrées parcourues, aimées ?

Un autre itinéraire fait l'objet de reprises, de variations nombreuses au fil des pages : celui des œuvres d'art qui ont construit l'homme et sa poésie. Ici, comme dans l'anthologie de 1977 intitulée Poesía con nombres, les noms de peintres, de musiciens, d'écrivains se pressent. Des peintres amis, le plus souvent, la musique écoutée en écrivant, qui peut aller de Schubert à Bob Dylan, en passant par Ravel, Schönberg, etc... : le répertoire est vaste et varié. La littérature offre toutefois les références les plus fréquentes, celle des premiers auteurs qui ont accompagné, guidé Blas de Otero : Jiménez, Vallejo, Fray Luis, ceux qu'il appréciera plus tard, ceux qu'il relit, les " maestros " auxquels il ne cesse de rendre hommage ; il est impossible d'en établir la liste ici. L'intertextualité qui fut toujours une dimension importante de son travail poétique est maintenant plus allusive, c'est un demi vers de Lorca ici, un autre de Juan de la Cruz là, un adjectif : "la dostoyevskiana cocina ", une apostrophe familière et affectueuse : "los pucheros que decías tú, la Cepeda", etc.

Ce corpus constitue une trame, une toile de fond sur laquelle se dessine une esthétique personnelle, car la réflexion sur l'écriture, sur le fonctionnement et le rôle de la poésie, qui a toujours inspiré Blas de Otero, reste essentielle dans la création des dernières années.

Il aime à se représenter lui-même écrivant, dans des autoportraits qui font penser à ceux d'un Rembrandt, d'un Velasquez, le pinceau à la main. Dans cette double signature ou authentification de la parole, le papier, la plume, les lignes tracées sur la page prennent un relief particulier, ils disent le plaisir et la matérialité du geste.

"Escribo hablando ", l'art poétique revendiqué depuis En castellano s'y accomplit en se nuançant. Car si l'on trouve des petites pièces enlevées comme des croquis, en particulier dans les tableaux intimistes de l'harmonie du couple, il y a aussi des formes "savantes ", comme des sonnets - du 
grand art - mais qui échappent toujours au corset des 14 barreaux. Même les plus angoissés, ceux dont l'âpreté rappelle les sonnets métaphysiques de Quevedo, sont, si on les compare aux textes du recueil Ancia, comme " assouplis ", portés par une grande légèreté : "una pluma para escribir en el aire".

Ce qui va de pair avec une étonnante liberté de ton, puisque l'on peut passer du plus familier ("la madre del cordero ") à un registre quasi précieux dans la métaphorisation : "el hombro elegante de la ola ", proche parfois de la greguería: "Contigo, el mar desliza plácidamente su electrolux sobre la arena ", greguería dont elle partage le côté délibérément intempestif : " el alma está tranquila, está sentada". Dans La Galerna, les images se font plus hallucinées, surréalistes parfois : "La mañana es un pez saltando por el cielo". Les paronomases, métalepses, syllepses font toujours partie de l'arsenal otérien, ces jeux sur le langage qui révèlent la complexité de la réalité et celle des sentiments, comme dans ce titre: "Abrazo partido " qui suggère la lutte intérieure (a brazo partido) d'un moi écartelé entre l'amour filial et celui de la femme.

Toujours, selon l'auteur, "la permanencia de lo insólito » doit être préservée, afin de reproduire la vie, son mouvement, son "imprévisibilité ». L'humour - voire même la gouaille - permet d'aborder avec pudeur, sans les éluder, les sujets les plus graves : "Morir tiene sus ventajas»... (On pense parfois au défi lancé par le torero à la bête qui est en face de lui). Et cette mort affrontée apparaît aussi inscrite dans le mode d'écriture : "aproximándose al borde ", ce bord où le profil s'estompe : "Pero yo ya no soy yo : soy una sombra azulada deslizada diseminadalentre mis dedos ", où la parole tâtonne "escribiendol borroso ", se résorbe et se perd : "la plumalque cesa".

Mais ces "feuilles ", comme celle de Whitman, sont traversées par la vie, elles rassemblent, dans un grand "acorde final ", des textes essentiels pour saisir le sens d'une existence de poète qu'elles résument dans de vigoureux survols ainsi que l'ampleur d'une œuvre qui échappe définitivement à la catégorie de " poésie sociale » dans laquelle certains se plaisaient à l'enfermer. 